\title{
Some Aspects of Blood Loss and Fluid Balance in Paediatric Adenotonsillectomy
}

\author{
HAROLD B. HOLDEN, ${ }^{*}$ M.B., F.R.c.S., D.L.o. ; J. J. MAHER, $†$ M.B., D.A.
}

Attention has recently been drawn to the importance of assessing blood loss in paediatric surgery (Brit. med. F., 1964), but little has been written about such loss in adenotonsillectomy (Shalom, 1964). In this investigation we have set out to measure the operative blood loss and the degree of pre-operative fluid depletion; the significance of these with regard to postoperative progress is discussed. The opportunity was also taken to compare the effects of two different anaesthetic sequences on the operative blood loss.

\section{Method}

The series consisted of 50 cases of dissection adenotonsillectomy taken in sequence and with no attempt at selection. Twenty-five were anaesthetized with ether and 25 with halothane by means of a Boyle-Davis gag in all cases.

On arrival in hospital the patients were placed on fluid charts, and careful note was kept of all fluid intake in the 24-hour pre-operative period. Food and water were prohibited for the four hours prior to operation. For each child the predicted volumes of fluid necessary to maintain normal balance were calculated on a body-weight basis from a chart devised by Carre (1958). The deficit between the actual and the predicted intake was expressed as a percentage of the latter. Throughout the series the environmental conditions were constant, the children being nursed in the same ward under the same staff.

Premedication was by oral pentobarbitone sodium $(5 \mathrm{mg} . / \mathrm{kg}$.) and atropine ( $0.6 \mathrm{mg}$.) intramuscularly, given 60 minutes preoperatively. Induction was with nitrous oxide (90\%), oxygen $(10 \%)$, and incremental ether or halothane in a Boyle bottle. Induction time was noted from the approximation of the face-

\footnotetext{
* Guy's Hospital, London. Now Senior Registrar at Charing Cross t Guy's Hospital, London.
}

piece to the child until the insertion of the gag. All the patients were operated on by one surgeon (H. B. H.) and anaesthetized by one of us (J. J.M.). Note was made of any incidents during induction or operation, such as cyanosis, retching, or laryngospasm. Depth of anaesthesia was judged by the absence of protective reflexes, as well as the rate and depth of respiration.

The adenoids were first removed by curettage and the tonsils carefully dissected, gauze swabs and blunt dissectors being used. Bleeding-points were immediately clamped and ligated. The average time taken for the operation was 12.4 minutes.

Measurement of blood loss was by the gravimetric method as described by Davenport and Barr (1963). Blood loss was ascertained by measuring the volume of suctioned blood in graduated columns which contained an anticoagulant and silicone antifoam to prevent coagulation and clotting. Previously weighed dry gauze sponges were used and the quantity of blood soiling them was determined by immediate re-weighing. Gravimetric methods are convenient and simple, and they compare favourably with other methods (Baronofsky et al., 1946). Moreover, the method was checked against measured known volumes of blood, and the error was found to be $\pm 2 \%$. Blood volume was taken to be $70 \mathrm{ml}$./kg. (Carré, 1963).

The 50 cases included both sexes, and the average age was 7.3 years (range 2 to 12 years). The average weight was 26.1 $\mathrm{kg}$. On admission the haemoglobin was measured in all patients, the average being $12.4 \mathrm{~g} . / 100 \mathrm{ml}$. (range 8.1-15.3 g.).

\section{Results}

Forty-nine patients had some deficit in their fluid requirement, the average being $57 \%$, though 20 cases had a deficit of between $50 \%$ and $75 \%$ and in a further 11 it was more than

\begin{tabular}{|c|c|c|c|c|c|c|c|c|c|c|c|c|c|c|c|}
\hline \multirow[b]{3}{*}{$\begin{array}{l}\text { Case } \\
\text { No. }\end{array}$} & \multicolumn{7}{|c|}{ Ether } & \multicolumn{8}{|c|}{ Halothane } \\
\hline & \multirow[b]{2}{*}{ Age } & \multirow[b]{2}{*}{$\begin{array}{l}\text { Weight } \\
\text { in kg. }\end{array}$} & \multicolumn{2}{|c|}{ Blood } & \multicolumn{3}{|c|}{ Fluid } & \multirow[b]{2}{*}{$\begin{array}{l}\text { Case } \\
\text { No. }\end{array}$} & \multirow[b]{2}{*}{ Age } & \multirow[b]{2}{*}{$\begin{array}{l}\text { Weight } \\
\text { in kg. }\end{array}$} & \multicolumn{2}{|c|}{ Blood } & \multicolumn{3}{|c|}{ Fluid } \\
\hline & & & $\begin{array}{l}\text { Blood } \\
\text { loss } \\
\text { in ml. }\end{array}$ & $\mid \begin{array}{c}\% \text { Blood } \\
\text { loss of } \\
\text { total blood } \\
\text { volume }\end{array}$ & $\begin{array}{c}\text { Pre-op. } \\
24 \mathrm{hr} . \\
\text { fluid intake } \\
\text { (ml.) }\end{array}$ & \begin{tabular}{|c|} 
Predicted \\
$24 \mathrm{hr}$. re- \\
quirement \\
(ml.)
\end{tabular} & Deficit & & & & $\begin{array}{l}\text { Blood } \\
\text { loss } \\
\text { in } \mathrm{ml} .\end{array}$ & $\mid \begin{array}{c}\% \text { Blood } \\
\text { loss of } \\
\text { total blood } \\
\text { volume }\end{array}$ & $\left|\begin{array}{c|}\text { Pre-op. } \\
24 \mathrm{hr} . \\
\text { fluid intake } \\
\text { (ml.) }\end{array}\right|$ & $\begin{array}{l}\text { Predicted } \\
24 \mathrm{hr} . \text { re- } \\
\text { quirement } \\
\text { (ml.) }\end{array}$ & Deficit \\
\hline $\begin{array}{r}1 \\
2 \\
3 \\
4 \\
5 \\
6 \\
7 \\
8 \\
9 \\
10 \\
11 \\
12 \\
13 \\
14 \\
15 \\
16 \\
17 \\
18 \\
19 \\
20 \\
21 \\
22 \\
23 \\
24 \\
25\end{array}$ & $\begin{array}{r}10 \\
9 \\
10 \\
12 \\
9 \\
7 \\
4 \\
5 \\
12 \\
6 \\
7 \\
8 \\
10 \\
8 \\
6 \\
6 \\
6 \\
4 \\
6 \\
6 \\
7 \\
9 \\
2 \\
12 \\
4\end{array}$ & $\begin{array}{l}29.5 \\
27.5 \\
27.5 \\
54 \cdot 9 \\
37.5 \\
23.0 \\
17.6 \\
22.6 \\
35.4 \\
24 \cdot 1 \\
20 \cdot 4 \\
26.7 \\
33.5 \\
25.4 \\
20.8 \\
21.7 \\
14 \cdot 1 \\
17.2 \\
17 \cdot 2 \\
19.9 \\
25.4 \\
41.0 \\
12.5 \\
39.0 \\
17.3\end{array}$ & $\begin{array}{r}107 \\
295 \\
225 \\
260 \\
116 \\
49 \\
102 \\
124 \\
142 \\
146 \\
128 \\
142 \\
143 \\
107 \\
112 \\
57 \\
80 \\
90 \\
120 \\
53 \\
131 \\
173 \\
57 \\
85 \\
45\end{array}$ & $\begin{array}{r}5.2 \\
5.3 \\
15.3 \\
11.6 \\
6.8 \\
4.4 \\
3.2 \\
8.3 \\
7.8 \\
5.7 \\
8.6 \\
8.9 \\
7.6 \\
6.1 \\
6.0 \\
6.8 \\
3.8 \\
8.1 \\
7.5 \\
10.0 \\
3.8 \\
7.3 \\
6.1 \\
6.5 \\
3.1 \\
3.7\end{array}$ & $\begin{array}{r}1,278 \\
1,023 \\
1,961 \\
1,307 \\
625 \\
426 \\
511 \\
625 \\
426 \\
710 \\
681 \\
398 \\
910 \\
1,278 \\
855 \\
870 \\
620 \\
682 \\
525 \\
483 \\
522 \\
1,425 \\
325 \\
240 \\
330\end{array}$ & $\begin{array}{l}1,910 \\
1,820 \\
1,820 \\
2,500 \\
2,310 \\
1,610 \\
1,360 \\
1,580 \\
2,200 \\
1,630 \\
1,480 \\
1,780 \\
2,110 \\
1,710 \\
1,500 \\
1,490 \\
1,200 \\
1,340 \\
1,340 \\
1,440 \\
1,700 \\
2,480 \\
950 \\
1,982 \\
1,115\end{array}$ & $\begin{array}{l}33 \\
44 \\
\text { Nil } \\
48 \\
73 \\
73 \\
63 \\
60 \\
81 \\
66 \\
54 \\
78 \\
57 \\
25 \\
43 \\
42 \\
48 \\
49 \\
61 \\
67 \\
69 \\
43 \\
66 \\
88 \\
71\end{array}$ & $\begin{array}{l}26 \\
27 \\
28 \\
29 \\
30 \\
31 \\
32 \\
33 \\
34 \\
35 \\
36 \\
37 \\
38 \\
39 \\
40 \\
41 \\
42 \\
43 \\
44 \\
45 \\
46 \\
47 \\
48 \\
49 \\
50\end{array}$ & $\begin{array}{r}7 \\
7 \\
6 \\
6 \\
5 \\
8 \\
8 \\
8 \\
7 \\
7 \\
5 \\
9 \\
8 \\
12 \\
8 \\
4 \\
6 \\
5 \\
11 \\
9 \\
10 \\
5 \\
6 \\
10 \\
8\end{array}$ & $\begin{array}{l}44 \cdot 0 \\
17.4 \\
21 \cdot 8 \\
21.4 \\
19 \cdot 0 \\
21 \cdot 8 \\
30.7 \\
20.8 \\
14.9 \\
21.4 \\
17.7 \\
29.5 \\
23.1 \\
58.5 \\
23.1 \\
14 \cdot 9 \\
17 \cdot 2 \\
18 \cdot 2 \\
43.5 \\
32.5 \\
23.6 \\
20.8 \\
25.4 \\
39.7 \\
32.5\end{array}$ & $\begin{array}{r}168 \\
89 \\
61 \\
30 \\
36 \\
208 \\
110 \\
169 \\
50 \\
130 \\
80 \\
389 \\
194 \\
163 \\
66 \\
47 \\
75 \\
94 \\
324 \\
189 \\
194 \\
76 \\
58 \\
155 \\
162\end{array}$ & 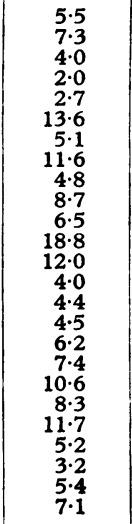 & $\begin{array}{r}1,120 \\
935 \\
780 \\
1,055 \\
890 \\
650 \\
750 \\
1,140 \\
180 \\
300 \\
240 \\
630 \\
730 \\
940 \\
910 \\
200 \\
200 \\
270 \\
1,300 \\
1,000 \\
1,310 \\
180 \\
240 \\
990 \\
885\end{array}$ & $\begin{array}{l}2,500 \\
1,360 \\
1,550 \\
1,530 \\
1,420 \\
1,550 \\
1,960 \\
1,500 \\
1,275 \\
1,275 \\
1,150 \\
1,590 \\
1,333 \\
2,500 \\
1,600 \\
1,033 \\
1,120 \\
1,160 \\
2,500 \\
2,060 \\
1,630 \\
1,250 \\
1,415 \\
2,410 \\
2,060\end{array}$ & $\begin{array}{l}55 \\
31 \\
50 \\
31 \\
38 \\
59 \\
62 \\
24 \\
86 \\
76 \\
79 \\
61 \\
45 \\
62 \\
43 \\
81 \\
82 \\
77 \\
48 \\
52 \\
20 \\
86 \\
83 \\
59 \\
57\end{array}$ \\
\hline
\end{tabular}


$75 \%$ of their calculated fluid requirement (Table I). One patient (Case 3) had taken his full estimated fluid requirement.

Blood Loss.-The operative blood loss is also shown in Table I. The average loss was $128.1 \mathrm{ml}$. When this loss is expressed in $\mathrm{ml} . / \mathrm{kg}$. body-weight or as a percentage of total blood volume (Table 1, column 4) it can be seen that there is a close relationship between such loss and the total body weight irrespective of age. The majority (27 cases) showed a loss of between $5 \%$ and $10 \%$ of their total blood volume. However, 9 of the 50 patients lost $10 \%$ or more of their total blood volume (Table II). The cases were divided into two anaesthetic series with 25 children in each group in order to compare the effect of the anaesthetic agent on the operative blood loss (Table III). Applying Student's $t$ test to the figures of blood loss for each group it was found that $t=1.36$ and $\mathrm{P}<0.1$. Hence there is statistically no significant difference in the blood loss whichever anaesthetic is used.

TABLE II.-Loss of Total Blood Volume

\begin{tabular}{l|c|c|c|c} 
& \\
\hline Blood loss & $0-5 \%$ & $5-10 \%$ & $10-15 \%$ & $15-20 \%$ \\
No. of cases & 14 & 27 & 7 & 2 \\
\hline
\end{tabular}

TABLE III.-Effect of Anaesthetic Agent on Blood Loss

\begin{tabular}{|c|c|c|c|c|c|}
\hline & & & & Halothane Series & Ether Series \\
\hline $\begin{array}{l}\text { Average Age.. } \\
\text { Average weight } \\
\text { Mean blood loss } \quad . \\
\text { Mean induction time } \\
\text { Mean operation time }\end{array}$ & $\begin{array}{l}\cdots \\
\cdots \\
\cdots \\
\cdots\end{array}$ & $\begin{array}{l}\ldots \\
\cdots \\
\cdots \\
\cdots\end{array}$ & $\begin{array}{l}\cdots \\
\cdots \\
\cdots \\
\cdots\end{array}$ & $\begin{array}{c}7.3 \text { years } \\
26.12 \mathrm{~kg} . \\
132.7 \mathrm{ml} . \\
5.3 \mathrm{~min} . \\
12.6 \mathrm{~min} .\end{array}$ & $\begin{array}{l}7.3 \text { years } \\
26.06 \mathrm{~kg} . \\
123.6 \mathrm{ml} . \\
8.0 \mathrm{~min} . \\
12.2 \mathrm{~min} .\end{array}$ \\
\hline
\end{tabular}

\section{Discussion}

\section{Fluid}

It seems clear that children who are admitted to hospital for adenotonsillectomy take less fluid than they require during the pre-operative period: $31(62 \%)$ cases had taken less than $50 \%$ of their calculated requirements. This is partly due to apprehension in a strange environment and partly due to the fact that children are not normally actively encouraged to drink. Indeed, on the day of operation fluid intake is stopped four hours pre-operatively. It was noted that in 10 cases the child had not taken food or fluid for over 12 hours, and in a further 28 cases for over six hours. Thus there is a period of 24 hours or even longer during which a fluid deficit occurs. Normally this deficit does not affect the post-operative course, for a physiological antidiuresis occurs, resulting from the stress of operation. However, any deficit in fluid intake must reflect to a certain extent the state of fluid balance. Therefore, should extra stress be incurred post-operatively, such as reactionary haemorrhage, especially if accompanied by vomiting, further adjustments cannot be made so effectively (Nelson, 1959).

The problem of fluid deficit can be particularly important in smaller children, as the water reserves are proportional to body weight, while the water requirements are conditioned by metabolic rate and hence are proportional to surface area. The small child has a greater surface area relative to weight ; thus a greater disparity exists between water requirements and reserves. This is further illustrated if the deficit in requirement is expressed as a percentage of total body weight $(0.55 \times$ body weight in $\mathrm{kg}$. + 0.51 : Friis Hansen et al., 1951), for it can be seen that 17 cases had a deficiency of more than $8 \%$ (Table IV), and this must be made good from their reserves. It follows that water intake by the child should be actively encouraged in the period from admission up to four hours before operation.

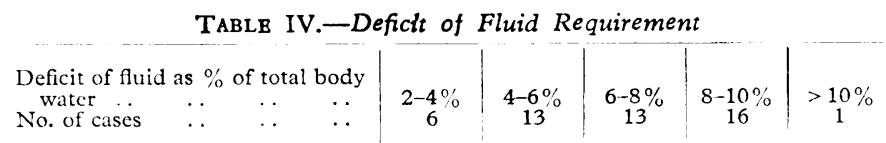

\section{Blood Loss}

Halothane is known to produce hypotension, and it is said that bleeding is decreased at the operation site during anaesthesia with this agent (Wylie and Churchill-Davidson, 1960). However, in this series the mean blood loss was slightly greater than in a comparable series in which ether was used. Thus so far as the effect on blood loss at operation is concerned there is no advantage in using halothane. Halothane has certain advantages which were well seen in this series, notably a quicker and smoother induction with less irritation of the respiratory tract and quicker recovery of protective reflexes; it is also non-inflammable. On the other hand, respiratory depression occurs easily and there is an ever-present danger of sudden marked hypotension from an overdose, particularly when the drug is administered from an uncalibrated vaporizer. Laryngospasm is also said to occur (Gordon Jones, 1962), though there was no instance of this in our series.

The majority of operations for adenotonsillectomy are to-day still performed under ether anaesthesia, and the safety of this technique is known (Denison Davies, 1964a). Until such time as the safety of halothane has been shown to be comparable to that of ether the widespread adoption of halothane alone for this operation cannot be advocated, but it seems reasonable to suggest that induction of anaesthesia with halothane and maintenance with ether would be the ideal method.

Imperfections of anaesthetic technique which produce laryngospasm, gagging, or straining may contribute materially to the operative blood loss ; also, other local conditions, such as fibrotic or infected tonsils, directly influence the amount of bleeding and render haemostasis more difficult. This is reflected in the number of tie ligatures required to control bleeding in each case. In six cases more than four ligatures were used, the mean blood loss being $254 \mathrm{ml}$.

It is to be noted that blood loss from adenoidectomy is largely unavoidable, though some surgeons pack the post-nasal space when removing the tonsils. In a short series in which adenoidectomy alone was used (14 cases) the mean blood loss was as much as $77.5 \mathrm{ml}$.

It is stated (Davenport and Barr, 1963) that in paediatric operations a loss of $14 \%$ of the total blood volume may occur in major procedures, and invariably transfusion is required; transfusion is often necessary when the loss is between 10 and $15 \%$.

There is no doubt that in routine adenotonsillectomy some children lose a very significant quantity of blood, though the operation is regarded as a "minor" one. Two patients in this series lost over $15 \%$ of the total blood volume and seven lost between 10 and $15 \%$. Hence any patient in whom the postoperative course varies from the expected normal must be treated as a potentially serious case, for the fatality rate is known to increase when re-operation for haemorrhage becomes necessary (Denison Davies, 1964b). Blood transfusion should be urgently considered in a patient known to have lost an excessive quantity of blood at operation and who continues to bleed in the immediate post-operative period. Transfusion must always be started before returning a patient to the theatre.

Even if actual haemorrhage does not occur a persistent tachycardia and fluid depletion resulting from deficient preoperative intake and post-operative vomiting suggests the need for intravenous replacement. In smaller children this could be achieved quite satisfactorily by intravenous injection of dextrosesaline solution from a $50-\mathrm{ml}$. syringe; this would be repeated as often as was necessary.

\section{Summary}

In a series of 50 children undergoing routine adenotonsillectomy pre-operative fluid intake has been measured and the average deficit was found to be $57 \%$ of the predicted requirement. 
Operative blood loss was measured gravimetrically and the mean loss was found to be $128.1 \mathrm{ml}$. Nine patients had lost more than $10 \%$ of their total blood volume.

A comparison of the effects of two anaesthetic agents, halothane and ether, on the operative blood loss was studied. No significant difference between the two agents was observed.

The need for early blood transfusion where haemorrhagic complications occur is emphasized.

It is suggested that a pre-operative deficit of fluid intake combined with post-operative vomiting and haemorrhage can lead to a fluid deficiency requiring early intravenous replacement.

We wish to thank Mr. P. V. Reading and Mr. L. F. W. Salmon for allowing us to investigate the patients under their care. Also we gratefully acknowledge the help and enthusiasm of the theatre and other nursing staff of the Evelina Children's Hospital, London.

\section{REFERENCES}

Baronofsky, I. D., Treloar, A. E., and Wangensteen, O. H. (1946). Surgery, 20,761.

Brit. med. F., 1964, 1, 1201.

Carré, I. J. (1958). Practitioner, 181, 184.

Cart (1963). Brit. F. Anaesth., 35, 488.

Davenport, H. T., and Barr, M. N. (1963). Canad. med. Ass. 7., 89, 1309. Denison Davies. D. (1964a). Brit. 7. Anaesth., 36, 110.

- (1964b). Ibid., 36, 244.

Friis-Hansen, B. J., Holiday, M., Stapleton, T., and Wallace, W. M. (1951). Paediatrics, 7, 321.

Gordon Jones, R. G. (1962). Brit. F. Anaesth., 34, 481.

Nelson, W. E. (1964). Textbook of Pediatrics, 8th ed., Saunders, Philadelphia and London.

Shalom, A. S. (1964). F. Laryng., 78, 734.

Wylie, W D. and Churchill-Davidson, H. C. (1960). A Practice of Anaesthesia, p. 205 . Lloyd-Luke, London.

\section{Preliminary Communications}

\section{Studies on the Inhibitory Effect of Erythrose on the Development of Experimental Cholera}

Brit. med. F., 1965, 2, 1351

It has recently been reported by Royx Chowdhury and Datta (1965) that erythrose inhibits the growth of Vibrio cholerae in vitro. The present work was undertaken with a view to finding out whether erythrose could inhibit the development of experimental cholera in rabbits. D-Erythrose was purchased from L. Light \& Co. Ltd., Colnbrook, England, and used in these experiments.

A pathogenicity test was done with a known pathogenic strain of $V$. cholerae in the ligated intestinal loops of rabbits according to the procedure of De and Chatterje (1953). Approximately $3.75 \times 10^{7}$ viable vibrios were injected into the

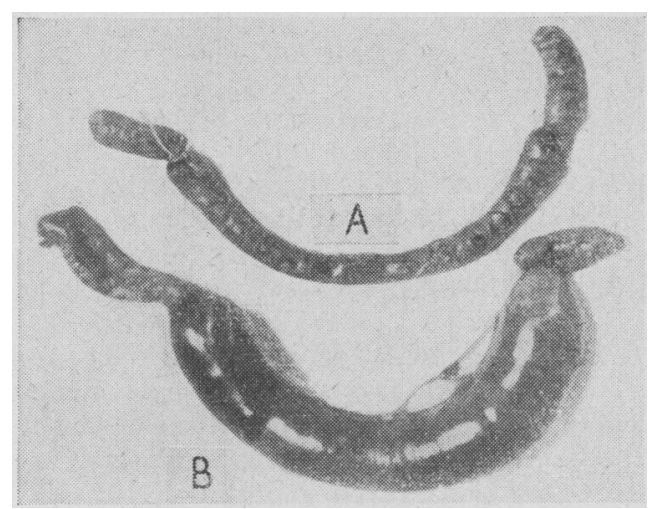

Effect of erythrose on the gut-inflammatory reaction of $V$. cholerae. A, with erythrose; B, without erythrose.

intestinal loops of a rabbit, under ether anaesthesia, alone or together with $100 \mu$ mols of erythrose in a final volume of $0.7 \mathrm{ml}$. of normal saline. The animals were sacrificed after 24 hours, and on examination it was found that the loop injected with a mixture of erythrose and vibrio culture did not show any gut-inflammatory reaction, while severe reaction was observed in the loop injected with the same dose of vibrio alone (see Fig.). It was interesting to note that viable vibrios could be isolated from the loop injected with the mixture of vibrio and erythrose even after 24 hours, though there was no gut-inflammatory reaction.

The effect of erythrose on the experimental cholera in baby rabbits was also examined by the method of Dutta and Habbu (1955). In these experiments approximately $2 \times 10^{8}$ viable vibrios were injected into the proximal part of the small intestine of 8-day-old rabbits under light anaesthesia with or without $150 \mu \mathrm{mols}$ of erythrose in $0.5 \mathrm{ml}$. of normal saline. All the five animals which were injected with $V$. cholerae alone died within 24 hours, and post-mortem examination revealed congestion of the blood-vessels of the small intestine and distension of the large intestine with watery fluid. On the other hand, 9 out of 10 animals injected with $V$. cholerae and erythrose were found normal and alive the next day. Out of the nine surviving rabbits one rabbit was killed each day for nine days and their intestinal washings were put on culture plates for detection of viable vibrios. It is interesting to note that from the intestines of these animals killed up to the fourth day from injection viable vibrios could be isolated, even though there was no appreciable congestion of the small intestine or distension of the large intestine. From the fifth day and onwards viable vibrios could not be obtained from the intestine of those rabbits.

The failure to produce gut-inflammatory reaction in the ligated loops of small intestines of adult rabbits and congestion and distension respectively of the small and large intestines of baby rabbits may be attributed to the inhibitory effect of erythrose on the growth of $V$. cholerae, as has already been demonstrated in in-vitro experiments by Roy Chowdhury and Datta (1965). It appears, however, that erythrose has no vibriocidal action, since viable vibrios could be isolated from the gut even after 24 hours of injection of $V$. cholerae and erythrose into the intestine when the animals were still normal and alive.

Pradyot K. Bhattacharya, M.B., B.S. JAYASREE ROY CHOWDHURY, M.SC. AsOKE G. DATTA, D.PHIL.

Indian Institute for Biochemistry and Experimental Medicine, Calcutta.

REFERENCES

De, S. N., and Chatterie, D. N. (1953). F. Path. Bact., 66, 559. Dutta, N.' K., and Habbu, M. K. (1955). Brit. F. Pharmacol., 10, 153. Roy Chowdhury, J., and Datta, A. G. (1965). Biochim. biophys. Acta (Amst.), 104, 296. 